represents a misdiagnosis. As the patient was not psychologically assessed it is fanciful to diagnose a disease such as anorexia nervosa, which requires characteristic psychopathological phenomena.

Commonly used diagnostic criteria for this condition-for example, the DSM III criteria'emphasise intense fear of becoming obese; disturbance of body image; weight loss of at least a quarter of the original body weight; refusal to maintain body weight over a minimal normal weight; and, importantly, no known physical illness that could account for the loss of weight.

The patient described by Drs Nagaratnam and Ghougassian did not seem to fulfil any of these criteria. As the patient admitted that his weight was low there is no definite evidence that he either was fearful of becoming fat or had a distorted body image; the absence of data regarding calculated expected weight for height and age preclude comment on his weight loss; and there was no indication that the patient did not want to maintain a normal body weight. Similarly, the final DSM III criterion-namely, the absence of contributory physical illness_-was not fulfilled. Postgastrectomy malabsorption syndromes are well documented. In this patient's case the myopathy, neuropathy, and biochemical disturbances were all possible sequelae of gastrectomy and malabsorption. As the cause of death was unclear (because there was no postmortem examination) the patient might have died of carcinomatosis. The patient's history of possible sexual dysfunction was poorly described and cannot be regarded as influencing diagnosis; neither can the fact that he had no children.

We disagree with the authors' contention that studies of the outcome of anorexia nervosa are limited; there are two good reviews on the long term outcome. ${ }^{23}$

AJIT SHAH

DAVID BALDWIN

Academic Unit for Psychiatry of Old Age,

St Charles's Hospital,

London W106DZ

1 American Psychiatric Association. Diagnostic and statistical manual of mental disorders. 3rd ed. Washington, DC: APA 1980.

2 Hsu LKG. Outcome of anorexia nervosa. Arch Gen Psychiatn 1980;37:1041-6.

3 Schwartz DM, Thompson MG. Do anorectics get well? Curren research and future needs. Am f Psychiatry 1981;138:319-23.

SIR, - We disagree with Drs N Nagaratnam's and D F Ghougassian's diagnosis of anorexia nervosa in a 70 year old man (21 May, p 1443). Five clinical features seem to have been proposed as the cornerstones of the diagnosis of anorexia nervosa in this case; only one, that of a body weight falling below the 75 th centile, can be regarded as one of the core diagnostic criteria for anorexia nervosa. None of the other clinical features mentioned fulfil the requirements for a diagnosis of primary anorexia nervosa ${ }^{12}$ or, indeed, the definitions suggested by the major authors who have written on this topic. . $^{3.5}$

The patient showed a resistance to eating, but, unfortunately, there was no clarification of the underlying psychological disturbance, if indeed one existed at the time. We think that a history of chronic dyspepsia leading to an almost tota gastrectomy ought not to be dismissed too lightly as a possible underlying cause for his reluctance to eat. The generalised muscle wasting and weakness seem to be consistent with simple disuse atrophy, which in itself would not be an unusual finding in someone in such a chronically malnourished state.

There have been numerous reports of anorexia nervosa occurring in an older age group with a rather different pattern of psychopathology and psychodynamic background. ${ }^{6}$ Most authors who have described such cases emphasise the importance of excluding organic disease and depressive disorders.

The list of psychiatric differential diagnoses for a patient with anorexia is lengthy, and it is important to delineate clearly the recognised core psychopathology of anorexia nervosa before diagnosing it. In this case there was no evidence that the patient suffered from a morbid fear of fatness or that he exhibited denial of thinness. He might have been suffering from an affective disorder, and, given the high prevalence of depressive illness in this age group, this is a much more plausible hypothesis in the light of the evidence presented.

As Drs Nagaratnam and Ghougassian suggest anorexia nervosa is often a relapsing and remitting condition and may last many years. But little information is to be gained about the long term outcome of a disorder without an accurate diagnosis according to an acknowledged disease classification system.

K MatTheWS

Ross Clinic,

J M EAGLES

Aberdeen AB9 2ZF

American Psychiatric Association. Diagnostic and statistical manual of mental disorders. 3rd ed. Washington, DC: APA, 1980

2 World Health Organisation. Mental disorders: glossary and guide to their classification in accordance with the ninth revision of the therr classification in accordance with the ninth revision of the
International Classification of Diseases (ICD 9). Geneva: WHO 1978.

Feighner JP, Robins E, Guze S, Woodruff R, Winokur G, Munoz R. Diagnostic criteria for use in psychiatric research. Arch Gen Psychiatry 1972;26:57-63.

4 Crisp AH. The differential diagnosis of anorexia nervosa Proceedings of the Royal Sociery of Medicine 1977;70:686-90. 5 Bruch $\mathrm{H}$. Anorexia nervosa and its differential diagnosis. $\mathcal{F} \mathrm{Ner}$ Ment Dis 1966;141:555-66.

6 Carrier J. L'anorexie mentale. Paris: Libraire E Le Francois, 1939.

\section{BRL 26830A and weight loss}

SIR,-We were interested in the paper by Dr A A Connacher and others (30 April, p 1217). Clearly, it is encouraging that $\beta$ agonist drugs have been developed that are metabolically active without producing unacceptable cardiovascular effects. In assessing the potential implications for treatment of BRL 26830A, however, two aspects may not have received appropriate emphasis.

The first relates to the compound's efficacy. Three years ago we described our experience with BRL 26830A given for six weeks to subjects with refractory obesity at a dose of $200 \mathrm{mg}$ daily. ${ }^{1} \mathrm{We}$ failed to find any significant difference in the mean weight change in the 20 subjects receiving active treatment (mean weight loss $0.2 \mathrm{~kg}$ ) when compared with that in the 21 subjects receiving placebo (mean weight gain $0.3 \mathrm{~kg}$ ). This study has now been reported in detail. ${ }^{2}$ There are several possible reasons why the results of this study varied from those reported at the same time by Munro et al. More recently we undertook a further study, in which BRL $26830 \mathrm{~A}$ was given to subjects at the time of initial referral to an obesity clinic for 12 weeks at an increased dose of $400 \mathrm{mg}$ a day. Analysis of these data again failed to show any significant difference compared with placebo in the overall mean weight loss achieved by those receiving the drug, though, predictably, subjects in both groups lost weight: the 17 subjects receiv ing placebo achieved a mean weight loss of 8.3 $(5 \cdot 8) \mathrm{kg}$ and the 18 receiving BRL 26830A $9 \cdot 25$ $(5 \cdot 5) \mathrm{kg}$.

The second aspect relates to side effects Although we used a low dose regimen of $50 \mathrm{mg}$ BRL 26830A four times daily in our first study, many of our subjects felt a sensation of tremor or tremulousness that was clearly associated with the drug and occurred about an hour after a dose was taken and lasted for about an hour. In two subjects the symptoms were sufficiently severe to result in withdrawal from the study. We found similar effects in the second study. Indeed, so many of the subjects receiving active treatment experienced tremor that it was possible, before breaking the code, to predict accurately which subjects had received the active preparation. It follows that with the present formulation it is impracticable to undertake a genuine double blind investigation of BRL 26830A, and this may be one of the factors that needs to be considered when assessing the disparity of the results in the clinical studies so far.

\section{J F MUNRO \\ P DONALD \\ B J CHAPMAN \\ D L FARQUHAR \\ H RHEIN}

Edenhall Hospital,

Musselburgh, Midlothian

1 Chapman BJ, Farquhar D, Galloway S, Simpson GK, Munro JF. The effects of BRL $26830 \mathrm{~A}$, a new $\beta$-adrenoceptor agonist, in refractory obesity. Int $\mathcal{O}$ Obes 1985;9:230.

2 Chapman BJ, Farquhar DL, Galloway SMcL, Simpson GK, Munro JF. The effects of a new $\beta$-adrenoceptor agonist, BRL 26830A, in refractory obesity. Int f Obes 1988;12:119.

3 Munro JF, Chapman BJ, Robb GH, Zed C. Clinical studies with thermogenic drugs. In: Berr EM, Blondheim SH, Eliahou HE, Shafrif $\mathrm{E}$, eds. Recent advances in obesity research: $V$. London: John Libbey, 1988:155.

SIR,-The findings of Dr A A Conacher and others (30 April, p 1217), together with those of $\mathrm{Ng}$ et al, ${ }^{\prime}$ are consistent with the hypothesis that $\beta_{2}$ adrenoceptors regulate the activity of the ouabain sensitive sodium-potassium adenosine triphosphatase sodium pumps of body cells, which may determine in part the thermogenic control of body weight. Sodium pumps may account for about $40 \%$ of resting energy expenditure in man. ${ }^{2}$

We found that when human lymphocytes are incubated for short times in vitro in a buffer containing physiological concentrations of $\beta$ adrenoceptor agonists like adrenaline and salbutamol sodium-potassium adenosine triphosphatase activity (measured as the ouabain sensitive influx of rubidium-86) is increased. This effect is blocked by $\beta$ adrenoceptor antagonists like propranolol (article in preparation). We had originally studied the possible role of $\beta$ adrenoceptors in vascular myocytes in causing essential hypertension. When only non-obese subjects were studied the average number ${ }^{3}$ and activity ${ }^{4}$ of lymphocyte sodium pumps were significantly lower in hypertensive patients than healthy subjects.

Intraleucocytic sodium concentration is increased in essential hypertension ${ }^{56}$ and in women (probably because of sodium pump inhibition) but not in obesity itself. $\mathrm{Ng}$ et al suggested that in obesity a deficient activation of the sodium pump in response to feeding or insulin leads to an increase in intracellular sodium concentration after energy intake and to defective dietary thermogenesis. ${ }^{1}$ This hypothesis could explain the common finding of hypertension in obesity, the limited hypotensive effect of weight loss in hypertension, and one of the cellular mechanisms of action of BRL 26830A in obesity-the drug may increase insulin sensitivity in healthy non-obese subjects.

In Dr Connacher and others' study BRL 26830A seemed to stimulate $\beta_{2}$ adrenoceptors selectively in striated muscle, resulting in a decrease in body weight in obese subjects, most of whom were women. While accepting the limitations of short term studies of blood cells in vitro, we propose that the effects on thermogenesis due to prolonged treatment with BRL $26830 \mathrm{~A}$ are produced by the $\beta_{2}$ adrenoceptor mediated activation of the sodiumpotassium adenosine triphosphatase in the plasma membranes of tissues like striated muscle.

We would not expect an atypical $\beta_{2}$ adrenoceptor 